\title{
EVALUASI PENGGUNAAN OBAT AINS PADA PASIEN ARTHRITIS RAWAT JALAN RSU KOTA X PERIODE JANUARI-MARET 2017
}

\author{
Nurwulan Adi Ismaya, Bagaskara Danumaya \\ Sekolah Tinggi Ilmu Kesehatan Kharisma Persada \\ Tangerang Selatan, 15417 \\ E-mail:wulan.ismaya@gmail.com
}

\begin{abstract}
ABSTRAK
Arthritis merupakan penyakit kronis yang gejalanya dapat hilang dan timbul dalam jangka waktu lama, apabila seseorang menderita artritis maka gejalanya dapat timbul kembali setelah lama menghilang. Obat yang biasa digunakan dalam terapi Arthritis ialah analgesik dengan kombinasi OAINS golongan COX-1 dan COX-2. Obat Anti Inflamasi Non Steroid (OAINS) adalah suatu kelompok obat yang berfungsi sebagai analgesik (pereda nyeri), antipiretik (penurun panas), dan anti-inflamasi (anti radang) yang bekerja dengan cara menghambat biosintesis prostaglandin Penggunaan Obat Anti Inflamasi Non Steroid yang tidak tepat dapat menimbulkan berbagai permasalahan, biasanya pemberian dosis obat yang lebih. Pemberian obat AINS dengan dosis lebih dapat menyebabkan peningkatan risiko trombotik kardiovaskuler terlebih jika pasien memiliki riwayat penyakit kardiovaskuler dan belum ada penelitian yang mengatakan bahwa penggunaan dosis obat AINS yang berlebih. Tujuan penelitian ini adalah mengetahui kerasionalan penggunaan obat AINS (Anti Inflamasi Non Steroid) pada pasien Arthritis Rawat Jalan di RSU Kota X. Penelitian bersifat deskriptif dengan desain Cross Sectional. Data diperoleh dari catatan rekam medis dan resep pasien secara retrospektif periode Januari-Maret 2017. Data dianalisa menggunakan Parameter kerasionalan obat berdasarkan Departemen Kesehatan tahun 2008 yang meliputi: Tepat dosis, Tepat Indikasi, Tepat Pasien, dan Tepat Obat. Dari 201 pasien arthritis yang memenuhi kriteria inklusi penelitian didapat data $96 \%$ tepat obat, 100\% tepat indikasi, $100 \%$ tepat pasien, dan $84 \%$ tepat dosis.
\end{abstract}

Kata Kunci : Rasionalitas, NSAID, Arthritis

\begin{abstract}
Arthritis is a chronic disease whose symptoms can disappear and arise in the long term, if a person suffers from arthritis then the symptoms may recur after a long absence. The drugs commonly used in Arthritis therapy are analgesics with a combination of COX-1 and COX-2 NSAIDs. Non-Steroidal Anti-Inflammatory Drugs (NSAIDs) are a group of drugs that act as analgesics (pain relievers), antipyretics (anti-inflammatory), and anti-inflammatory (anti-inflammatory) that work by inhibiting prostaglandin biosynthesis Non-Steroidal Anti Non Inflammatory Drug Use can precisely cause a variety of problems, usually giving a dose of more drugs. Provision of more NSAIDs of drugs may lead to increased cardiovascular thrombotic risk especially if the patient has a history of cardiovascular disease and no studies have suggested that excessive doses of NSAIDs are used.The Aim of this research is to know the rationale of a Non Steroid Anti Inflammatory Drug use in outpatient Arthritis at RSU (General Hospital) Kota X. The Research was descriptive with Cross Sectional design. Data were obtained from patient medical record and prescriptions retrospectively for the periode of Januari to March 2017. Data were analyzed using drug rationale parameters based on Indonesia Ministry of Health 2008, which include: precise dose, precise indication, precise patient, and precise drug. From 201 patients which include in inclusion criteria of the research obtained 96\% precise drugs, $100 \%$ precise indication, $100 \%$ precise patient, and $84 \%$ precise dose.
\end{abstract}

Keyword : Rationality, NSAID, Arthritis 


\section{PENDAHULUAN}

Arthritis merupakan penyakit yang terjadi disekitar sendi yang ditandai dengan rasa sakit, sendi menjadi kaku, bengkak dan kelemahan pada sendi(Irianto 2014). Arthritis merupakan penyakit kronis yang gejalanya dapat hilang dan timbul dalam jangka waktu lama, apabila seseorang menderita artritis maka gejalanya dapat timbul kembali setelah lama menghilang,. Hal ini membuat penderita artritis harus sering berobat apabila penyakitnya kambuh dan minum obat sesuai aturan agar gejala penyakitnya hilang (Suarjana, 2009).

WHO melaporkan angka kejadian rematik pada tahun 2008 mencapai 20\% persen penduduk dunia yang terserang rematik, dimana 5-10\% merupakan penderita yang berusia 5-20 tahun. Dan $20 \%$ dari penderita rematik adalah mereka yang berusia 55 tahun (Wiyono, 2010). Hampir pada tahun 2005 jumlah penderita Arthtritis sudah mencapai 66 juta atau hampir 1 dari 3 orang menderita gangguan sendi, dengan 42,7 juta diataranya telah terdiagnosis sebagai Arthritis dan 23,2 juta sisanya adalah penderita dengan keluhan nyeri sendi kronis (Arthritis Foundation, 2006).

Sedangkan penderita di Indonesia menurut hasil penelitian dari Zeng QY et al 2008, menyatakan bahwa prevalensi Rheumatoid Arthritis di Indonesia mencapai $23,6 \%$ hingga $31,3 \%$. Prevalensi Rheumatoid Arthritis tertinggi di Indonesia terdapat di Provinsi Jawa Barat yaitu 4I,7\%, diikuti oleh Provinsi Papua Barat sebanyak 38,2\% dan Nusa Tenggara Timur 38,0\%. Sedangkan Provinsi Sumatra Barat menempati urutan ke 9 tertinggi dari 33 provinsi di Indonesia yaitu sebanyak 21,4\% (Puslitbang Biomedis dan Farmasi Badan Penelitian dan Pengembangan Kesehatan, Departemen Kesehatan, 2009).

Obat yang biasa digunakan dalam terapi Arthritis ialah analgesik dengan kombinasi OAINS golongan COX-1 dan COX-2. Obat Anti Inflamasi Non Steroid (OAINS) adalah suatu kelompok obat yang berfungsi sebagai analgesik (pereda nyeri), antipiretik (penurun panas), dan anti-inflamasi (anti radang) yang bekerja dengan cara menghambat biosintesis prostaglandin (Katzung, 2007).

Penggunaan Obat Anti Inflamasi Non Steroid yang tidak tepat dapat menimbulkan berbagai permasalahan, biasanya pemberian dosis obat yang lebih. Pemberian obat AINS dengan dosis lebih dapat menyebabkan peningkatan risiko trombotik kardiovaskuler terlebih jika pasien 
memiliki riwayat penyakit kardiovaskuler dan belum ada penelitian yang mengatakan bahwa penggunaan dosis obat AINS yang berlebih, tetapi penelitian yang dilakukan di RSU Kabupaten Subang sebanyak 52\% tepat obat karena pemberian $\mathrm{Na}$ diklofenak beresiko terhadap kardiovaskular namun kriteria lain sesuai dengan formularium Rumah Sakit (Rizky, 2014).

Penelitian di RSU kota Tangerang Selatan tentang penggunaan Obat Anti Inflamasi Non Steroid pada pasien Arthtritis yang meliputi kerasionalan penggunaan Obat Anti Inflamasi Non

\section{METODE}

Metode yang digunakan pada penelitian ini yaitu metode analisa kerasionalan obat berdasarkan Departemen Kesehatan RI yang meliputi : tepat pasien, tepat obat, tepat indikasi, tepat dosis (dosis, aturan pakai, cara pemakaian, lama pemberian).

Pengumpulan data dilakukan dengan mengumpulkan data sekunder, yakni berupa catatan Rekam Medis pasien penderita Arthritis d Instalasi Rawat Jalan RSU Kota Tangerang Selatan periode Januari-Maret 2017. Penelitian ini adalah penelitian deskriptif dengan pendekatan retrospektif. Karena faktor risiko diukur dengan melihat
Steroid pada pasien arthtritis belum dilakukan.

Berdasarkan uraian di atas, prevalensi penyakit Arthritis yang insidensinya semakin meningkat maka dilakukan penelitian tentang Evaluasi Penggunaan Obat Anti Inflamasi Non Steroid. Oleh Karena itu peneliti hendak melakukan penelitian pada pasien rawat jalan di RSU Kota Tangeang Selatan periode Januari-Maret 2017, yaitu mengenai Rasionalitas Penggunaan Obat Anti Inflamasi Non Steroid pada pasien Arthritis.

kejadian masa lampau untuk mengetahui ada tidaknya faktor risiko yang dialami (Saryono,2010) Desain yang digunakan adalah Cross Sectional, yaitu pengumpulan data variabel untuk mendapatkan gambaran rasionalitas penggunaan Obat Anti Inflamasi Non Steroid pada pasien yang berobat di rawat jalan pada suatu waktu tertentu.

Instrumen penelitian yang digunakan dalam penelitian ini adalah formulir profil pengobatan pasien dan data checklist analisa rasionalitas penggunaan obat yang telah dibuat oleh peneliti, data rekam medis dan resep pasien (jenis kelamin pasien, usia pasien, 
dan penggunaan obat AINS) rawat jalan RSU Kota Tangerang Selatan.

Analisis data dilakukan secara deskriptif dengan menguraikan data dari rekam medis dan resep pasien. Data yang diperoleh lalu diperiksa kelengkapannya dan dipastikan tidak ada kesalahan

\section{HASIL}

\section{Distribusi Populasi dan}

Sampel

Pada penelitian ini distribusi populasi sampel yang diperoleh dari data rekam medik pasien rawat jalan yang terdiagnosis Arthritis sebanyak 501 pasien dengan menggunakan rumus slovin tingkat kesalahan 5\% di dapatkan 218 sampel pasien, namun pasien yang sudah dari awal ditentukan kriteria inklusi hanya sebanyak 201 pasien, karena 5 pasien rujuk ke Rumah Sakit lain, 5 pasien masuk ke Ruang Rawat Inap, 3 pasien masuk Instalasi Gawat pemasukan data. Selanjutnya dilakukan evaluasi berdasarkan Departemen Kesehatan Republik Indonesia untuk menilai ketepatan penggunaan Obat Anti Inflamasi Non Steroid (OAINS) pada pasien

Arthritis

Darurat, dan 4 pasien dengan data rekam medik tidak lengkap. Berdasarkan hal tersebut dapat dihitung response rate penelitian sebesar 92,2\%. Penelitian ini dilakukan di instalasi rawat jalan RSU Kota Tangerang Selatan dengan memasukkan data pengobatan pasien yang berasal dari data rekam medik pasien ke dalam profil pengobatan pasien, kemudian dilakukan pengorganisasian dan observasi secara deskriptif. 


\section{Evaluasi Kerasionalan Penggunaan Obat}

Dari total 201 pasien yang termasuk dalam kriteria inklusi penelitian. Data kerasionalan obat dapat dilihat pada tabel berikut.

Tabel 1. Kerasionalan Penggunaan Obat

\begin{tabular}{|c|c|c|c|}
\hline No & Indikator Kerasionalan & $\mathbf{N}$ & $\%$ \\
\hline 1 & Rasional & 193 & 96 \\
\hline 2 & Tidak Rasional & 8 & 4 \\
\hline & Total & 201 & 100 \\
\hline
\end{tabular}

Berdasarkan tabel 1. Pasien yang menggunakan obat AINS sudah rasional $96 \%$ dan yang belum rasional 4\%. Dari 201 pasien Jika dilihat berdasarkan indikator rasionalitas yaitu tepat indikasi, tepat obat, tepat dosis dan tepat pasien maka dapat diketahui ketepatan dalam penggunaan obat pada tabel 2 .

Tabel 2. Kerasionalan Penggunaan Obat

\begin{tabular}{lcccccr}
\hline \multicolumn{1}{c}{ Indikator } & \multicolumn{2}{c}{ Tepat } & \multicolumn{2}{c}{ Tidak Tepat } & \multicolumn{2}{c}{ Total } \\
\cline { 2 - 7 } Kerasionalan & $\mathbf{N}$ & $\mathbf{\%}$ & $\mathbf{N}$ & $\mathbf{\%}$ & $\mathbf{N}$ & $\mathbf{\%}$ \\
\hline Tepat Indikasi & 201 & 100 & 0 & 0 & 201 & 100 \\
\hline Tepat Obat & 201 & 100 & 0 & 0 & 201 & 100 \\
\hline Tepat Dosis & 169 & 84 & 32 & 16 & 201 & 100 \\
\hline Tepat pasien & 201 & 100 & 0 & 0 & 201 & 100 \\
\hline
\end{tabular}

\section{Berdasarkan tabel 2}

pasien dengan tepat indikasi sebanyak 201 pasien (100\%), tepat obat 201 pasien (100\%), tepat dosis 169 pasien (84\%) dengan tidak tepat dosis sebanyak 33 pasien $(16,5 \%)$, dan tepat pasien sebanyak 201 pasien $(100 \%)$. 


\section{Evaluasi Kerasionalan Penggunaan Obat berdasarkan Dosis}

\author{
Evaluasi ini bertujuan \\ untuk mengetahui ketepatan \\ pemberian dosis obat OAINS di \\ instalasi rawat jalan RSU Kota
}

Tangerang Selatan pada Periode Januari-Maret 2017 yang kemudian dibandingkan terhadap pustaka.

Tabel 3 Penggunaan Obat Berdasarkan Dosis

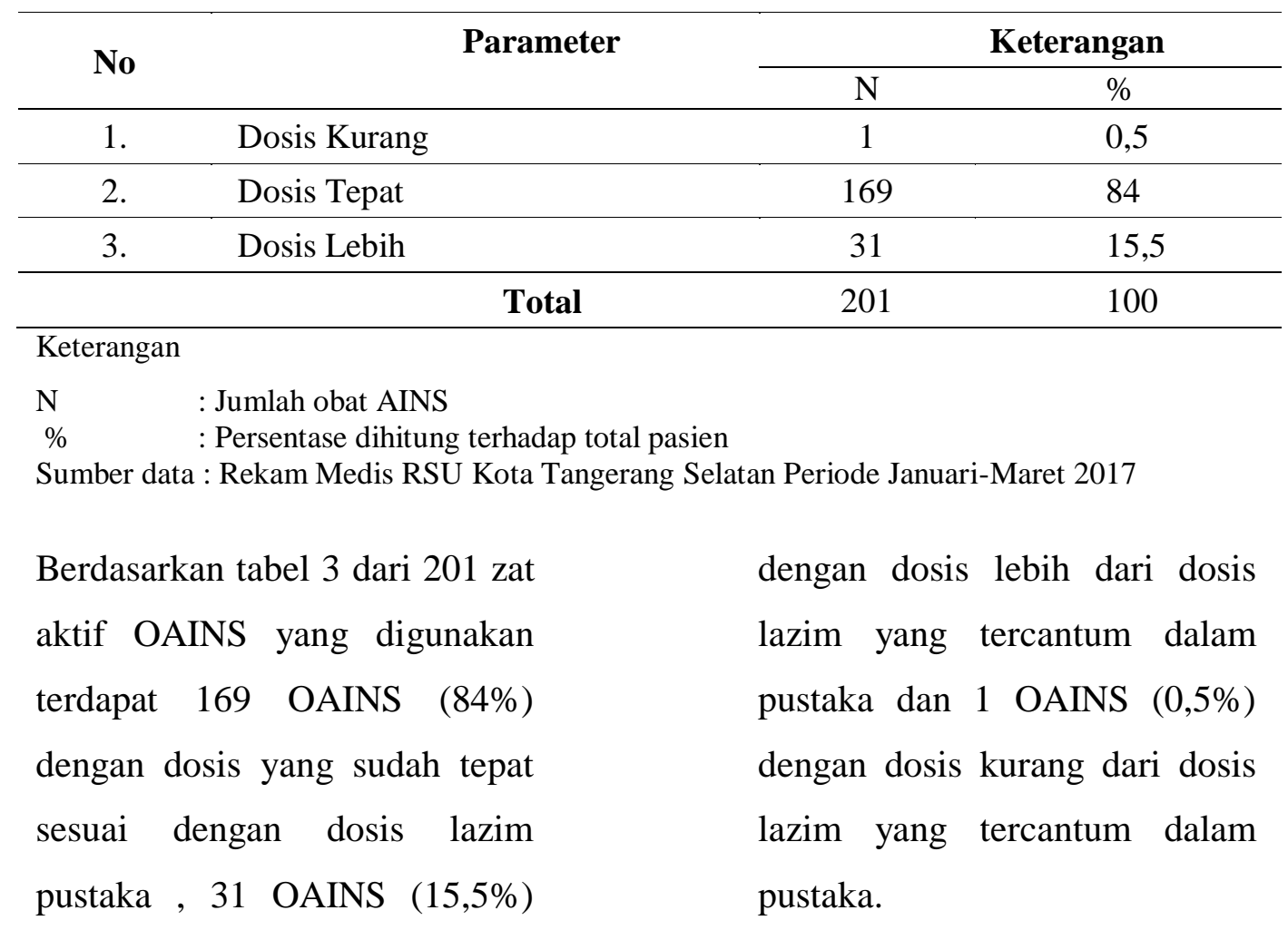

\section{DISKUSI}

Berdasarkan tabel 1. pasien yang menggunakan obat AINS sudah rasional $96 \%$ dan yang belum rasional 4\%. Pada tabel 2 menunjukan bahwa ketepatan indikasi sesuai dengan standar British National Formulary tahun 2015. Tepat indikasi dapat diartikan sebagai pemberian obat yang sesuai dengan diagnosis dokter dan terbukti manfaat terapinya. Perlu diperhatikan bahwa tidak semua pasien membutuhkan intervensi dalam pengobatan. Pada tabel 2 menunjukan bahwa ketepatan pasien sesuai dengan standar British National Formulary tahun 2015. Dikatakan tepat pasien apabila obat 
diberikan berdasarkan ketepatan tenaga kesehatan dalam menilai kondisi pasien dengan mempertimbangkan adanya penyakit penyerta atau komplikasi. Obat yang digunakan tidak boleh berkontraindikasi dengan pasien. Pada tabel 2 menunjukan bahwa ketepatan dosis sesuai dengan standar Dipiro 2009 dan Drug International Handbook tahun 2009. Pengobatan pada Arthritis dikatakan tepat dosis apabila, pemberian dosis obat AINS sesuai dengan standar Dipiro tahun 2009 dan Drug International Handbook tahun 2009. Dalam pengobatan Arthritis harus mempertimbangkan kondisi keadaan, usia, jenis kelamin serta penyakit riwayat pasien yang mengalami penurunan fungsi kerja sehingga dalam pemberian dosis terapi akan berpengaruh. Pada tabel 2 menunjukan bahwa tepat obat dalam terapi Arthritis dapat diartikan sebagai kesesuaian dalam pemilihan obat dari beberapa jenis obat yang mempunyai indikasi terhadap penyakit Arthritis berdasarkan
British National Formulary tahun 2015.

Berdasarkan tabel 3 dari 201 zat aktif OAINS yang digunakan terdapat 169 OAINS (84\%) dengan dosis yang sudah tepat sesuai dengan dosis lazim pustaka, 31 OAINS $(15,5 \%)$ dengan dosis lebih dari dosis lazim yang tercantum dalam pustaka dan 1 OAINS $(0,5 \%)$ dengan dosis kurang. Dosis kurang karena seharusnya pasien dengan nomor urut 96 mengkonsumsi $200 \mathrm{mg}$ untuk pemakaian 3 kali sehari 1 tablet, karena dosis seharusnya adalah 400-800 mg 3-4 kali sehari 1 tablet namun jika untuk efek analgesik maka pemakaian $200 \mathrm{mg}$ dengan pemakain 3 kali sehari masih diperbolehkan (DIH, 2009). Sedangkan untuk pasien yang mengkonsumsi dosis berlebihan untuk obat meloxicam dengan pemakaian 3 kali sehari 1 tablet 15 mg, seharusnya dosis untuk obat meloxicam ialah 7,5 $\mathrm{mg}$ atau $15 \mathrm{mg}$ untuk pemakaian 2 kali sehari 1 tablet

(Dipiro, 2009). 


\section{SIMPULAN}

Penggunaan obat AINS yang sudah rasional mencapai $96 \%$ dengan rasionalitas sebagai berikut:

1. Tepat Indikasi $100 \%$ tepat

\section{DAFTAR PUSTAKA}

Arthritis Foundation (WWW. Arthritis.org/prevalensiarthritis.php). Yang diakses pada tanggal 7 mei 2017

British National Formulary (BNF). Edisi 58. London. BMJ Group and RPS publishing, 2010

British National Formulary (BNF). 2015. Edisi 70. London. BMJ Group and RPS publishing.

Dipiro, Joseph T., Talbert, Cecily.,et al. The ninth edition of the benchmark evidence-based pharmacotherapy. McGrawHill Companies Inc. USA, 2016

Katzung, Bertram G. Farmakologi Dasar dan Klinik. EGC. Jakarta, 2010
2. Tepat Pasien $100 \%$ tepat

3. Tepat Dosis $84 \%$ tepat dan $16 \%$ tidak tepat

4. Tepat Obat $100 \%$ tepat
Kemenkes RI. 2011. Modul Penggunaan Obat Rasional, Jakarta.

Riset Kesehatan Dasar. (Riskesdas). Laporan Nasional. Jakarta:Badan Litbangkes Depkes, 2013

Suarjana, I. Arthritis Rheumatoid. Dalam S. A. Sudoyo, Ilmu Penyakit Dalam (hal. 24952512). Jakarta:Internal Publishing, 2009

Sudoyo, Arru. Ilmu Penyakit Dalam. Jilid 2.Edisi 4. Jakarta: FKUI, 2011

Sudoyono, A.W., Setiyohadi, B., Alwi, I., Simadribata, M., Setiati, S. Buku Ajar Penyakit Dalam. Jilid III edisi V. Jakarta: Interna Publishing,2009 
